\title{
Correlation of Subjective Side Effects with Plasma Concentrations of Nortriptyline
}

\author{
MARIE ÅSBERG,* L.M. ; BÖRJE CRONHOLM,† M.D. ; FOLKE SJÖQVIST, $\ddagger$ M.D. ; DICK TUCK,* M.D.
}

\begin{abstract}
ummary: Plasma levels of tricyclic antidepressant drugs $\checkmark$ vary considerably between individuals receiving the same amount of drug. The bearing of this variation on the occurrence of subjective side effects was investigated in 40 psychiatric inpatients with depressive disorders. Plasma levels were determined before and during four weeks of treatment with nortriptyline $50 \mathrm{mg}$. three times a day and patients were rated for subjective side effects, the assessors being unaware of the plasma levels of the drug.

Plasma levels varied widely between individual patients, but in any given patient the plasma level tended to be constant over a period of time. The side effects of nortriptyline diminished significantly with time and were in most cases absent during the fourth week of treatment. There was a significant positive correlation between plasma level of nortriptyline and subjective side effects.

The steady-state plasma level of a drug which is metabolized is usually a more important determinant for its effect than dosage, since it reflects the amount of drug available for biological action. Very high plasma levels of nortriptyline should presumably be avoided, since there is no evidence that they are needed for therapeutic effect and they are potentially harmful.
\end{abstract}

\section{Introduction}

During continuous treatment with tricyclic antidepressant drugs the drug concentration in plasma increases successively until a plateau is reached. This plateau level varies considerably between individuals (Hammer et al., 1967). For nortriptyline a range from 8 to $78 \mathrm{ng} . / \mathrm{ml}$. was observed in healthy volunteers after eight days' administration of $0.2 \mathrm{mg} . / \mathrm{kg}$. body weight three times daily (Alexanderson et al., 1969). The bearing of this variation on the clinical effects of the drug has not previously been investigated, but preliminary observations (Sjöqvist et al., 1968) indicated that a high plasma level might be of importance for the occurrence of side effects.

The aim of the present investigation was to study the occurrence of subjective side effects of nortriptyline, a monomethylated tricyclic antidepressant, in relation to the plasma level of the drug. Nortriptyline was used because of its known pharmacokinetic properties-that is, steady-state kinetics (Hammer et al., 1967) and little interindividual variation in plasma protein binding (Borga et al., 1969). Nortriptyline is active per se, and there is no indication that its main metabolites in man, 10-OH-nortriptyline and desmethylnortriptyline (this laboratory, unpublished), contribute to the therapeutic action (Sjöqvist et al., 1969; Borgå et al., 1970).

Side effects of tricyclic antidepressant drugs are often reported in connexion with evaluations of their therapeutic efficacy-for example, Rose et al. (1965) and Stewart and Mitchell (1968). Some of the side effects attributed to the drug, such as dryness of mouth, constipation, and fatigue, are, however, also well-recognized symptoms of depression. Others, such as tremor and increased perspiration, are somatic manifestations of anxiety (Hamilton, 1959) as well. Symp-

\footnotetext{
* Registrar, Department of Psychiatry, Karolinska Sjukhuset, 10401 Stockholm, Sweden.

+ Professor of Psychiatry, Karolinska Sjukhuset, 10401 Stockholm, Sweden.

¥ Professor of Clinical Pharmacology, University of Linköping, Sweden.
}

toms similar to side effects may exist before treatment, as was shown by Green (1964), who found a variety of "side effect symptoms" present in non-treated "well" subjects as well as in medical patients not under drug treatment. These symptoms tended to be accentuated by placebo treatment.

Quantitative ratings of side effects are thus likely to include symptoms of non-pharmacological origin. The importance of relating "side effect symptoms" during drug treatment to the incidence of symptoms during a control period when no drug has been given, or preferably when no drug has been found in the body fluids with sensitive analytical methods, is further shown by the investigations of Berry and Turner (1968). In a cross-over trial they found that patients excreted significant amounts of psychotropic drugs during a period when these drugs were not administered by the physician.

\section{Patients and Methods}

Forty-two depressed inpatients were studied. The material was classified into "neurotic" (8 men and 9 women, age range $25-63$, mean age 41.5 years) and "endogenous" ( 8 men and 17 women, age range 25-72, mean age 53.6 years) depressions. The classification was made after a clinical evaluation. Endogenous depression was operationally defined as a disease characterized by the following features: (1) lowering of mood, usually without adequate psychological cause, (2) retardation, (3) diurnal variation of symptoms with amelioration in the afternoon, and (4) early awakening, in accordance with the description of Cronholm and Ottosson (1960). The "neurotic" group included patients with various types of depression not exhibiting these features. The severity of depression was such as to warrant admission to hospital.

Drug Regimen.-Nortriptyline $50 \mathrm{mg}$. was given by mouth thrice daily for four weeks after a period of four to seven days of placebo administration. The placebo tablets consisted of lactose. The tablets were given at $06.00,14.00$, and 22.00 hours, and the patients were routinely observed to ingest the drug. With the exception of hypnotics (pentobarbitone or glutethimide) and occasional doses of sedatives (diazepam, meprobamate), which do not interfere in the method used to assay nortriptyline, no additional drugs were allowed. Blood and urine analyses for barbiturates, phenothiazines, and meprobamate performed during the placebo period and every other week during nortriptyline therapy showed no discrepancies to the prescribed treatment.

Determination of Plasma Level of Nortriptyline.-Plasma levels of nortriptyline were determined during the placebo period and twice weekly during treatment with nortriptyline according to the principles of Hammer and Brodie (1967) as further described by Sjöqvist et al. (1969). Blood samples were drawn at 13.00 hours, collected in heparinized tubes, stored at $4^{\circ} \mathrm{C}$. and centrifuged within one hour at $600 \mathrm{~g}$. Plasma duplicates, $2 \mathrm{ml}$. each, were acidified with $0.5 \mathrm{ml}$. of $0 \cdot 1 \mathrm{~N} \mathrm{HCl}$ and stored frozen at $-20^{\circ} \mathrm{C}$. until analysed.

Ratings.-The patients were rated for side effects once weekly, starting during the placebo period, on a rating scale, designed for the purpose (Table I), consisting of 11 items graded from 0 to 3 in increasing severity. The summed scores on these 11 items are called "raw side effect scores." The rating was made by two psychiatrists in a joint interview. At the interview no attempt was made to discriminate between pharmacologically-induced side effects and symptoms of other 
TABLE I-Rating Scale for Side Effects

1. Physical tiredness

Slightly tired, but needs no extra rest

Has to lie down and rest at times

Lies all day

2. Sleep disturbance

Normal sleep without hypnotics

Normal sleep with hypnotics

3-6 hour's sleep with hypnotics

3. Headache

None

Occasional, no analgesics needed

Constant moderate, or occasional severe, headache. Salicylates effective Constant severe headache. Salicylates ineffective

4. Vertigo

None ...

Occasional slight dizziness $\ldots$
Constantly slightly dizzy, or occasional severe dizziness

Constant severe dizziness. Has to lie down

"Orthostatic" symptoms

None

Feels slightly like fainting on sudden rising

Has to rise slowly to avoid feeling like fainting

Palpitations

None

Slight palpitations

Occasional disturbing palpitations

Constant disturbing palpitations

Tremor

None..$\quad \cdots \quad \cdots \quad \ldots \quad \ldots$

Slight tremor, movements not affected

ments impaired

8. Perspiration

Normal.

Slightly increased

Obviously increased

Profuse.

9. Dryness of mouth

None

Some, but not subjectively disturbing

Obvious, but not severe or painful

Severe, makes speaking difficult

10. Constipation

Nlight constipation, purgatives not needed

Obvious constipation. Purgatives taken

1. No bowel movements in spite of purgatives

Micturition disturbances

None

Slight difficulties in passing wate

Difficulties in emptying bladder. Treatment needed

ary retention

TABle II-Percentage Subjective Side Effects of Placebo and Nortriptylinc

\begin{tabular}{|c|c|c|c|c|c|c|c|}
\hline & & & \multirow{2}{*}{ Placebo } & \multicolumn{4}{|c|}{ Nortriptyline } \\
\hline & & & & Week 1 & Week 2 & Week 3 & Week 4 \\
\hline $\begin{array}{l}1 . \\
2 . \\
3 . \\
4 . \\
5 . \\
6 . \\
7 . \\
8 . \\
9 . \\
10 . \\
11 .\end{array}$ & 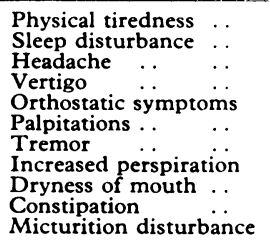 & $\begin{array}{l}\cdots \\
\cdots \\
\cdots \\
\cdots \\
\cdots \\
\cdots \\
\cdots \\
\cdots\end{array}$ & $\begin{array}{r}68 \\
100 \\
30 \\
30 \\
18 \\
35 \\
35 \\
35 \\
58 \\
43 \\
5\end{array}$ & $\begin{array}{r}76 \\
92 \\
29 \\
37 \\
24 \\
45 \\
53 \\
45 \\
89 \\
61 \\
5\end{array}$ & $\begin{array}{r}62 \\
90 \\
26 \\
33 \\
28 \\
28 \\
49 \\
41 \\
95 \\
51 \\
5\end{array}$ & $\begin{array}{r}50 \\
89 \\
17 \\
31 \\
39 \\
11 \\
50 \\
36 \\
72 \\
44 \\
8\end{array}$ & $\begin{array}{r}54 \\
89 \\
14 \\
25 \\
46 \\
14 \\
46 \\
29 \\
64 \\
29 \\
7\end{array}$ \\
\hline
\end{tabular}

origin. Patients with endogenous depression were also rated for severity of depression according to a rating scale designed by Cronholm and Ottosson (1960). Those making the rating were kept unaware of the plasma levels of nortriptyline until the study was finished.

\section{Results}

General Outcome.-A few patients recovered during the placebo period and were immediately withdrawn from the study. Of the remaining 42 patients, two (one neurotic woman and one man with an endogenous depression) were found to have significant (more than $20 \mathrm{ng} . / \mathrm{ml}$.) amounts of nortriptyline in plasma during the placebo period. These patients were excluded. Thirty-one patients received nortriptyline continuously for four weeks. During the last week two patients thought themselves too well to remain in hospital and one was referred to another clinic because of an intercurrent somatic disease (nasopharyngeal carcinoma). In five patients worsening of depressive symptoms occurred or amelioration
TABLE III-Side Effect Scores, Mean and Standard Deviation

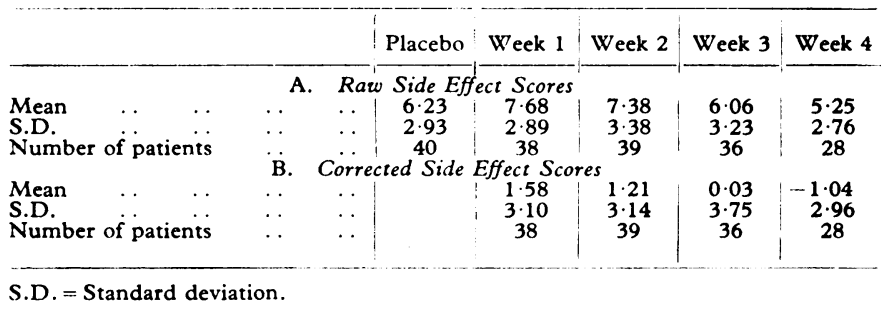

TABLE IV

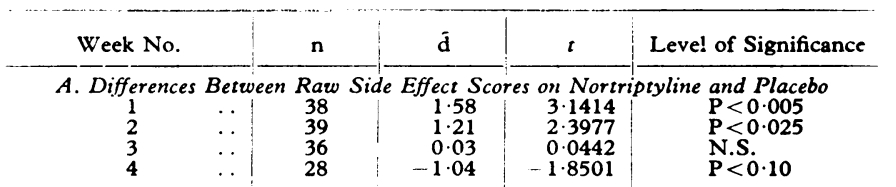

B. Differences Between Corrected Side Effect Scores Weeks 2, 3, 4, and Week 1

\begin{tabular}{l|c|c|c|c|c}
\multicolumn{1}{c}{ Differences Between Corrected Side Effect } & Scores Weeks & 2, 3, 4, and Week \\
$2-1$ & 37 & -0.38 & 1.4189 & N.S. \\
$3-1$ & 34 & -1.59 & 3.7413 & $\mathrm{P}<0.001$ \\
$4-1$ & 26 & -2.23 & 4.1633 & $\mathrm{P}<0.001$
\end{tabular}

$\overline{\mathrm{d}}=$ Mean of differences

N.S. $=$ Not significant.

was so slight that it was considered unethical to withhold alternative treatment. In one case side effects were severe enough to necessitate a reduction of dosage after three weeks. These patients are included in the study up to that time.

Plasma Levels of Nortriptyline.-As in earlier studies, there was a large interindividual variation in plasma levels of nortriptyline. The distribution of mean plasma levels of individual patients was slightly skewed (mean 96.1, S.D. 51.6, median 83, range 31-283 $\mathrm{ng} . / \mathrm{ml}$.). One patient differed considerably from the remainder, with an exceptionally high plasma level. The mean plasma levels of the patients with endogenous depression were lower than those of the neurotic depressions during all four weeks (Fig. 1). This difference is, however, not significant in a three-way analysis of variance (Winer, 1962) $(\mathrm{F}=1.039)$, nor is there any significant variation within weeks $(F=2 \cdot 370)$.

\section{Side Effects}

The percentages of patients who have any of the 11 rated "side effects" are shown in Table II. If no account is taken of symptoms occurring during placebo therapy and the severity of symptoms, conclusions regarding the incidence of side effects may be misleading.

In most cases the side effects of nortriptyline were rather moderate. In two cases out of 40 there were, however, more alarming side effects. In one of these cases, a 44-year-old woman, the dosage had to be reduced because the patient

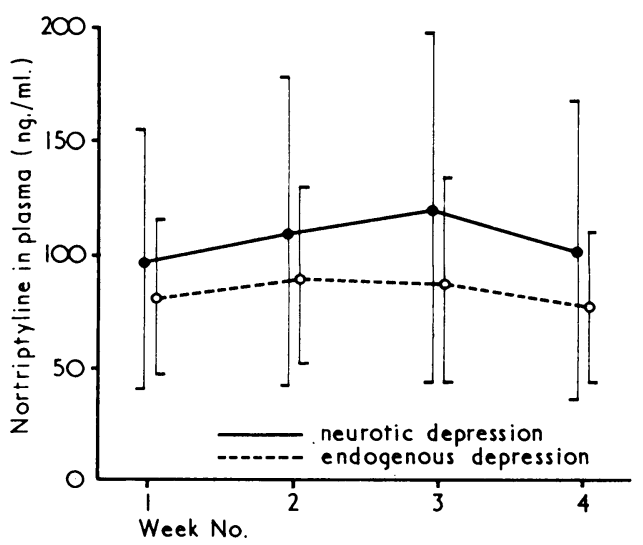

Fig. 1.-Plasma levels of nortriptyline in endogenous and neurotic depressions. Means and standard deviations. 
TABLE V-Relationship of Side Effects to Severity of Depression

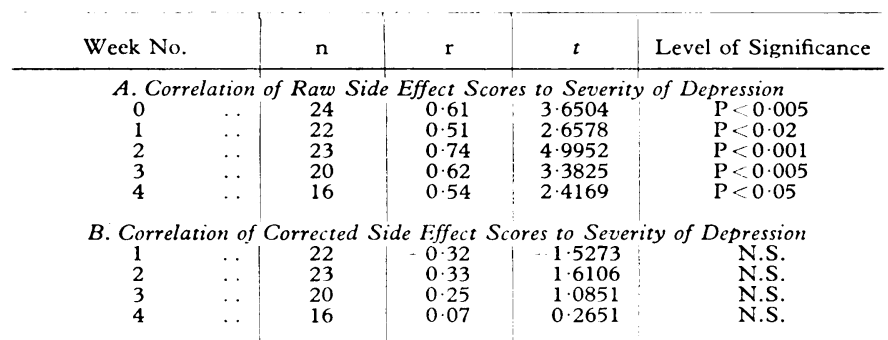

$\mathrm{n} \quad=$ Number of patients-that is, pairs of observations.

r N.S $=$ Correlation coefficient

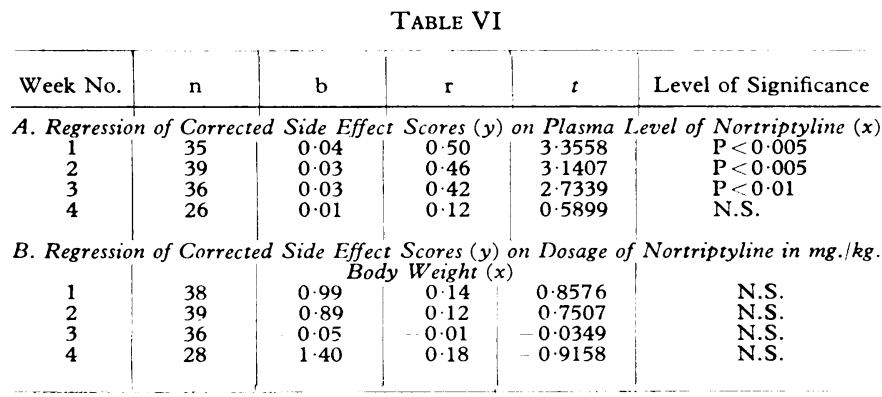

$\mathrm{n} \quad=$ Number of patients - that is, pairs of observations.

b $\quad=$ Regression coefficient

$\stackrel{\text { r }}{\text { N.S. }}=$ Correlation coeffici

fainted. Another patient, a 51-year-old man, developed during an E.C.G. exercise test a right bundle-branch block which disappeared after withdrawal of nortriptyline (cf. Freyschuss et al., 1970a). There was no difference in placebo side effect scores between endogenous and neurotic depressions (neurotic mean 6.13, S.D. 3.07; endogenous mean 6.29, S.D. 2.90). Therefore the material was treated as a whole.

The raw side effect scores on placebo and active therapy appear in Table III A. This shows a slight but significant increase in side effects during the first and second weeks of active therapy as compared with placebo. During the third and fourth weeks the side effect scores diminished and were lower than on placebo, though not significantly so (Table IV A).

Throughout the study there was a significant correlation between raw side effect scores and severity of depression in the endogenous depressions (Table V A). This may be due to the fact that this score measures depressive symptoms as well as side effects. Therefore an estimate of pharmacologically induced side effects was obtained by subtracting each patient's placebo score from his scores on nortriptyline. The resulting corrected side effect score is not correlated to the severity of the depression (Table V B).

The distribution of corrected side effect scores is about normal. The corrected side effect scores diminish mono-

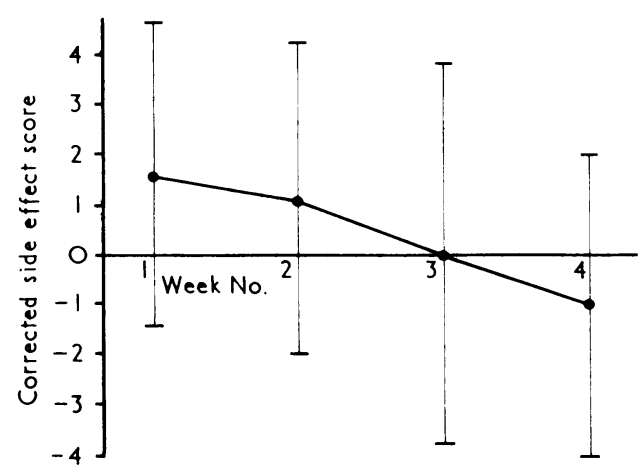

Fig. 2.-Corrected side effect scores. Means and standard deviations. tonically with time (Fig. 2, Table III B). The scores of weeks 3 and 4 are significantly lower than those of week 1 ; in fact the mean side effect score for the fourth week is negative (Tables III B, and IV B).

Relationship of Side Effects to Plasma Level of Nortriptyline.-The two above-mentioned patients with severe side effects had the highest plasma levels in the material (maximum values 340 and $235 \mathrm{ng} . / \mathrm{ml}$. in the woman and man respectively). There was a significant correlation between corrected side effect scores and plasma level of nortriptyline during the first three weeks of treatment (Table VI A). Though all patients received the same amount of nortriptyline, there is still a variation in dosage due to differences in body weight (range $1.69-3.06 \mathrm{mg} . / \mathrm{kg}$.). There is, however, no correlation between dosage in $\mathrm{mg}$. $/ \mathrm{kg}$. body weight and corrected side effect scores (Table VI B).

\section{Discussion}

The plateau plasma levels of nortriptyline are under genetic control and presumably determined by the rate of metabolism of the drug (Alexanderson et al., 1969). The finding that occasional patients develop extremely high plasma levels of nortriptyline on a conventional dosage suggests that there may be genetic polymorphisms forming a polygenic system controlling the metabolism of the drug, a hypothesis which is at present being evaluated.

The tendency of side effects to diminish with time accords with clinical experience. It might be due to the development of receptor tolerance to the peripheral effects of the drug, since there is no corresponding trend in the plasma levels. Psychological factors, such as decreased awareness of side effects with amelioration of the depression, may also contribute. This would be in keeping with the finding that after successful electric convulsion treatment depressed patients tend to judge their memory as improved, independently of objective change (Cronholm and Ottosson, 1963).

The inhibitory effect of tricyclic antidepressants on the neuronal uptake of various monoamines within the centra! nervous system is thought to be closely related to the antidepressant effect (Carlsson, 1965; Schildkraut and Ketv, 1967). Controlled studies are in progress on the relationship between plasma level and therapeutic efficacy of the drug. So far, however, there is no evidence that very high plasma levels (over, say, $100 \mathrm{ng} . / \mathrm{ml}$.) are necessary for a therapeutic effect, and it therefore becomes important to reduce dosage in patients who develop high plasma levels and so avoid a potentially harmful accumulation of the drug. This is particularly desirable in elderly patients in whom cardiotoxicity could reasonably be expected to have more serious consequences. In view of the many factors that contribute to the occurrence of subjective side effects in the individual patient, it is, however, questionable whether the side effects could be used as criteria to determine optimal dosage.

Detailed analysis of the rating protocols revealed no straightforward correlation between any particular side effect and the plasma level of nortriptyline. Such side effects as dryness of mouth and constipation may be due both to an anticholinergic effect and to a central adrenergic inhibition of parasympathetic activity. In this connexion blockade of tyramine pressor effects by nortriptyline in man is strongly correlated to the plasma level of the drug but not to the dose (Freyschuss et al., 1970b).

The steady-state plasma level is an estimate of the amount of biologically available drug, and when drug effects are compared in different individuals is more relevant than dosage. Since it is difficult to determine optimal dosage of tricyclic antidepressants by clinical methods, a pharmacokinetic approach-that is, monitoring the plasma levels of the drugmight be rewarding in terms of improved patient care. 
This study was supported by grants from Carl-Bertel Nathhorst Foundation, the Swedish Medical Research Council B70-21x1021-05, the National Institutes of Health, Bethesda, U.S.A. (GM 13978-05), the Association of the Swedish Pharmaceutical Industry, and by funds from Karolinska Institutet.

The polynomal analysis of variance was performed by $\mathrm{Mr}$. Jan Lindell.

REFERENCES

Alexanderson, B., Evans, D. A. P., and Siöqvist, F. (1969). British Medical fournal, 4, 764 .

Berry, R., and Turner, P. (1968). British fournal of Psychiatry, 114, 203.

Borgå, O., Azarnoff, D. L., Plym Forshell, G., and Sjöqvist, F. (1969). Biochemical Pharmacology, 18, 2135.

Borgå, O., Hamberger, B., Malmfors, T., and Sjöqvist, F. (1970). Journal of Pharmacology and Experimental Therapeutics. In press.

Carlsson, A. (1965). In Handbuch der experimentellen Pharmakologie, ed. O. Eichler and A. Farah, vol. 19, p. 529. Berlin, Springer.

Cronholm, B., and Ottosson, J.-O. (1960). Acta Psychiatrica Scandinavica, 35, Suppl. No. 145 , p. 69.

Cronholm, B., and Ottosson, J.-O. (1963). British fournal of Psychiatry, 109, 251 .
Freyschuss, U., Sjöqvist, F., Tuck, D., and Åsberg, M. (1970a). Pharmacologia Clinica, 2, 68.

Freyschuss, U., Sjöqvist, F., and Tuck, D. (1970b). Pharmacologia Clinica, 2,72 .

Green, D. M. (1964). Annals of Internal Medicine, 60, 255.

Hamilton, M. (1959). British fournal of Medical Psychology, $32,50$.

Hammer, W., and Brodie, B. B. (1967). Fournal of Pharmacology and Experimental Therapeutics, 157, 503.

Hammer, W., Ideström, C.-M., and Sjöqvist, F. (1967). In Antidepressan Drugs, ed. S. Garattini and M. N. G. Dukes, p. 301. Amsterdam, Excerpta Medica.

Rose, J. T., Leahy, M. R., Martin, I. C. A., and Westhead, T. T. (1965) British fournal of Psychiatry, 111, 1101.

Schildkraut, J. J., and Kety, S. S. (1967). Science, 156, 21.

Sjöqvist, F., et al. (1968). In Toxicity and Side Effects of Psychotropic Drugs, ed. S. B. de C. Baker, J. R. Boissier, and W. Koll, p. 246. Amsterdam, Excerpta Medica.

Sjöqvist, F., Hammer, W., Borgå, O., and Azarnoff, D. L. (1969). In Collegium Internationale Neuro-psychopharmacologicum: The Present Status of Psychotropic Drugs, ed. A. Cerletti and F. J. Boré, p. 128. Amsterdam, Excerpta Medica.

Stewart, J. A., and Mitchell, P. H. (1968). British fournal of Psychiatry, $114,469$.

Winer, B. J. (1962). Statistical Principles in Experimental Design, p. 306. New York, McGraw-Hill.

\title{
Comparative Trial of Nutrizym in Chronic Pancreatic Insufficiency
}

\author{
R. P. KNILL-JONES, ${ }^{*}$ M.B., M.R.C.P. ; H. PEARCE, $† ;$ J. BATTEN, $\ddagger$ M.D., F.R.C.P. \\ ROGER WILLIAMS, $\$ M.D., F.R.C.P.
}

British Medical fournal, 1970, 4, 21-24

\begin{abstract}
Ummary: A cross-over trial of pancreatic replacement therapy was carried out in 12 adults with chronic pancreatic insufficiency. The standard enteric-coated preparation, Pancrex V forte, was compared with Nutrizym, which has an enteric-coated core of pancreatic extract and a shell of bromelains-a mixture of proteolytic enzymes derived from the stem of the pineapple.

Nutrizym was significantly more effective than Pancrex $V$ forte in improving fat absorption, and reduced faecal weight. Protein digestion was assessed by measuring the urinary excretion of hydroxyproline after a gelatin meal. Nutrizym produced an earlier and significantly higher peak in hydroxyproline excretion than Pancrex $\mathrm{V}$ forte, but the cumulative effect was similar. The value of bromelains was investigated by including a period on the Nutrizym core alone. This was similar to Pancrex $V$ forte in improving fat absorption but had less effect on protein digestion, suggesting that the beneficial effect of Nutrizym compared with Pancrex $V$ forte was due to the added bromelains, and not to differences in enzyme content or enteric coating.
\end{abstract}

\section{Introduction}

Several reports have shown that pancreatic extracts can increase body weight, fat, and nitrogen absorption (Buckle, 1965; Harris et al., 1955) and can improve absorption curves (Mullinger, 1968). The response is often incomplete, however, even if large doses are given throughout the day (Jordan and Grossman, 1959), and even if sodium bicarbonate is added (Glaessner and Sigel, 1904; Veeger et al., 1962; Haro and Faloon, 1964). Plant and bacterial enzymes have been incorporated in some pancreatic preparations to improve their effectiveness (Goebell and Bode, 1969). A mixture of brome-

\footnotetext{
* Research Fellow, Liver Unit, King's College Hospital, London S.E.5.

† Research Technician, Liver Unit, King's College Hospital, London S.E.5. Consultant Physician, St. George's Hospital, London S.W.1., and Brompton Hospital, London S.W.3. $\checkmark$ Consultant Physician and Director, Liver Unit, King's College Hospital,
}

lains and pancreatin is available in two preparations (Nusser and Donath, 1968; Schultis and Wagner, 1968), one of which is Nutrizym (Merck). Bromelains is a mixture of proteolytic enzymes found in the stem of the pineapple (Ananas comosus); it has maximal proteolytic activity between $p H 3$ and 8 , and is stable at $p \mathrm{H} 2.0$ for a short period. Studies in vitro have shown that its effect in the digestion of casein at $p H 3.3$ is similar to that of pepsin and at $p H 6.0$ is similar to that of trypsin (Hennrich et al., 1965). Nutrizym has an enteric-coated core containing concentrated pancreatic extract, surrounded by a layer of bromelains and a sugar coating.

We describe here a cross-over trial comparing Nutrizym with Pancrex V forte (pancreatin, B.P.), which is the most widely used of the pancreatic replacement preparations available in the British Isles. The effect of the added bromelains was also investigated by including in the trial a period on Nutrizym core, which was identical in appearance to Nutrizym but contained enteric-coated pancreatin alone.

\section{Design of Trial}

Fourteen outpatients ( 3 female and 11 male) were admitted to the trial: two middle-aged patients with chronic pancreatitis and 12 (aged 15-29) with cystic fibrosis. The latter were chosen because they had considerable steatorrhoea even while taking Pancrex V forte (10 patients) or pancreatin granules (two patients). Other treatment was unaltered during the trial. Each patient was in the trial for three months and received Pancrex, Nutrizym, and Nutrizym core, each for one month in random order. A tablet of Nutrizym contained 50 mg. of bromelains. The amount of pancreatin in a tablet of Nutrizym was greater than in Pancrex V forte, and the doses given with each of the three main meals in a day were either three tablets of Pancrex $V$ forte or two tablets of the Nutrizym preparations. At the end of the trial the three preparations were assayed in vitro. Each tablet of Nutrizym and Nutrizym core was found to contain: trypsin 2,500 units, lipase 8,100 units, and amylase 18,000 units; the corresponding figures for Pancrex $\mathrm{V}$ forte were 1,230, 4,000, and 9,600 units respectively. 